\title{
A stable heavier group 14 analogue of vinylidene
}

\author{
Arnab Rit, ${ }^{1}$ Jesús Campos, ${ }^{1}$ Haoyu Niu, ${ }^{1}$ and Simon Aldridge ${ }^{1, *}$
}

Inorganic Chemistry Laboratory, Department of Chemistry, University of Oxford, South Parks Road, Oxford, UK OX1 3QR.

* To whom correspondence should be addressed. E-mail: simon.aldridge@chem.ox.ac.uk (SA)

\begin{abstract}
Vinylidene $\left(\mathrm{H}_{2} \mathrm{C}=\mathrm{C}\right)$ is a member of the family of compounds of composition $\mathrm{CH}$, (and isomeric with ethyne, $\mathrm{HC} \equiv \mathrm{CH}$ ) but has been observed only transiently_having a lifetime in the region of 0.1 ns. Indeed, no simple (non base-stabilised) compounds of the type $R_{2} E=E$ have been structurally characterized for any of the group 14 elements. Here we show that by employing the bulky and strongly electron-donating boryl ligand $(\mathrm{HCDippN})_{2} \mathrm{~B}\left(\mathrm{Dipp}=2,6-{ }^{i} \operatorname{Pr}_{2} \mathrm{C}_{6} \mathrm{H}_{3}\right)$, a simple monomeric digermavinylidene compound (boryl) ${ }_{2} \mathrm{GeGe}$ can be synthesized, which is stable at room temperature. Both its formation via the two-electron chemical oxidation of the symmetrical $\mathrm{Ge}^{0}$ compound $\mathrm{K}_{2}\left[\right.$ (boryl) $\mathrm{GeGe}\left(\right.$ boryl) , and its subsequent reaction chemistry (e.g. with $\mathrm{H}_{2}$ ), are consistent with high substituent lability and the accessibility of both 1,1 and 1,2-substitution patterns. Structural and computational studies of $\left\{(\mathrm{HCDippN})_{2} \mathrm{~B}\right\}_{2} \mathrm{GeGe}$ reveal a weak GeGe double bond - the $\pi$ component of which contributes to the highest occupied molecular orbital (HOMO) — with a Ge-centred lone-pair as the HOMO-1.
\end{abstract}




\section{Main Text}

Compounds of empirical composition $\mathrm{CH}$ have played key roles in establishing theories of chemical bonding central to our understanding of structure and reactivity. ${ }^{1}$ These include ethyne $(\mathrm{HC} \equiv \mathrm{CH})$ containing archetypal $\mathrm{C}-\mathrm{C} \sigma$ and $\pi$ bonds, ${ }^{2}$ and the prototype aromatic system benzene, ${ }^{3}$ as well as pseudo Jahn-Teller distorted cyclobutadiene, ${ }^{4}$ and the highly strained, but kinetically inert cubane, $\mathrm{C}_{8} \mathrm{H}_{8}{ }^{5}$ Analogues of a number of these systems featuring other group 14 elements have also proved to be synthetically accessible, ${ }^{6-9}$ with the contrasting geometric and electronic structures adopted by the heavier analogues of alkynes, for example, providing a rationale for their unusual 'transition metal like' reactivity. ${ }^{10}$ While the alkyne form of $\mathrm{C}_{2} \mathrm{H}_{2}$ is thus well established, the alternative methylidene carbene (vinylidene) isomer, $\mathrm{H}_{2} \mathrm{CC}$, has not been isolated and structurally characterized, being known to exist only as a transient species under high vacuum and/or high temperature conditions. ${ }^{11-13}$ The 1,2-migration of a hydrogen atom to generate ethyne is calculated to be highly exothermic and to occur via a very low energetic barrier (ca. $10 \mathrm{~kJ} \mathrm{~mol}^{-1}$ ); as such the lifetime of $\mathrm{H}_{2} \mathrm{CC}$ is very short (ca. $\left.10^{-10} \mathrm{~s}\right) .^{14-17}$ Formal replacement of $\mathrm{H}$ with $\mathrm{F}$ yields difluorovinylidene, $\mathrm{F}_{2} \mathrm{CC}$ for which the calculated kinetic barrier to isomerization is significantly higher (ca. $150 \mathrm{~kJ} \mathrm{~mol}^{-1}$ ), and which can therefore be generated and spectroscopically investigated in an argon matrix at temperatures up to $15 \mathrm{~K}{ }^{18}$ 'Free' vinylidene systems which are stable at temperatures close to ambient are, however, unknown, with structural characterization of $\mathrm{H}_{2} \mathrm{CC}$ systems relying instead on coordination to a transition metal as a trapping strategy. ${ }^{12}$

In the case of heavier analogues of ethyne, $\mathrm{E}_{2} \mathrm{H}_{2}(\mathrm{E}=\mathrm{Si}-\mathrm{Pb})$, the linear alkyne-like structure (isomer A, Figure 1) is calculated to lie relatively high in energy, reflecting the reduced strength 
of $\mathrm{E}-\mathrm{E} \pi$ bonds (and increased doublet-quartet separation for the $\mathrm{EH}$ 'monomer' unit) on descending Group 14. Alternative trans-bent (B), vinylidene (E), and other isomers incorporating bridging hydrogen atoms $(\mathbf{C}$ and $\mathbf{D})$ are predicted to be closer to the energetic minimum. ${ }^{19-23}$ Consistently, vinylidene structures have been suggested by high resolution laser spectroscopy/ab initio calculations for the transient species $\mathrm{H}_{2} \mathrm{C}=\mathrm{E}(\mathrm{E}=\mathrm{Si}, \mathrm{Ge})$, while a hydridebridged structure has been proposed for $\mathrm{Si}_{2} \mathrm{H}_{2}$ based on rotational spectra obtained at $73 \mathrm{~K} .{ }^{24,25}$ Incorporation of highly sterically demanding substituents, rather than $H$, however, distorts the potential energy landscape to the extent that only the relatively unhindered 1,2-disubstituted trans-bent geometry (B) has been realized among structurally characterized derivatives. ${ }^{6,7,26-29}$ The alternative 1,1 (vinylidene) isomer $\mathbf{E}$ features a highly electronically and sterically unsaturated Group 14 center in the 2-position which is prone to reaction with Lewis bases, and this strategy has recently been exploited by Scheschkewitz, ${ }^{30,31}$ and by Fillipou to generate Nheterocyclic carbene stabilized heavier vinylidenes. ${ }^{32,33}$ To our knowledge, however, no simple structurally characterized systems of the type $\mathrm{R}_{2}$ EE have been reported for any of the Group 14 elements.

Trans-bent dimetallyne systems REER $(\mathrm{E}=\mathrm{Si}-\mathrm{Pb})$ are unique in being the only isolable heavier group 14 compounds of composition $\mathrm{E}_{2} \mathrm{R}_{2} ;{ }^{6,7}$ such systems also constitute a landmark in small molecule activation chemistry as the first main group molecules capable of the ambient temperature activation of $\mathrm{H}_{2}$ (for $\left.\mathrm{E}=\mathrm{Ge}\right) .{ }^{34}$ To date, dimetallyne compounds have been reported in conjunction with bulky aryl, silyl and amido $\mathrm{R}$ substituents. ${ }^{26-29,35-39}$ We have recently been utilizing sterically encumbered boryl ligands (predominantly $(\mathrm{HCDippN})_{2} \mathrm{~B}$, where Dipp $=2,6$ $\left.{ }^{i} \mathrm{Pr}_{2} \mathrm{C}_{6} \mathrm{H}_{3}\right)$ to support main group compounds featuring unusual coordination numbers and/or 
oxidation states. $^{40,41}$ The extremely strong $\sigma$-donor capabilities of this ligand class dictate much of the chemistry of its complexes: elevated HOMO (highest occupied molecular orbital) energies and enhanced reactivity towards small molecule activation are features of low-valent borylsubstituted main group compounds. ${ }^{40,42}$ As such, we set out to explore the synthetic and reaction chemistry of dimetallyne systems with $\mathrm{R}$ = boryl; in doing so we reveal the potential for labile metal-to-metal transfer of the boryl group and the synthesis of first stable group 14 vinylidene compound, (boryl) $)_{2} \mathrm{Ge}=\mathrm{Ge}$.

\section{Results and Discussion}

Syntheses. The N-heterocyclic carbene (NHC) stabilized (boryl)germanium(II) chloride, $\left(\operatorname{IPr}_{2} \mathrm{Me}_{2}\right) \mathrm{GeCl}\left\{\mathrm{B}(\mathrm{NDippCH})_{2}\right\} \quad\left(\mathbf{1}, \quad\right.$ where $\quad \mathrm{I}^{\mathrm{Pr} 2 \mathrm{Me} 2} \quad=\quad$ 1,3-diisopropyl-4,5-dimethylimidazolylidene; see Supplementary Figure 14) is readily synthesized from $\left(\mathrm{I}^{\mathrm{Pr} 2 \mathrm{Me} 2}\right) \mathrm{GeCl}_{2}$ and (thf $)_{2} \mathrm{Li}\left\{\mathrm{B}(\mathrm{NDippCH})_{2}\right\},{ }^{43,44}$ and is susceptible to reduction chemistry leading to the formation of Ge-Ge bonds (Figure 2). Thus, the reaction of 1 with the $\mathrm{Mg}^{\mathrm{I}} \operatorname{dimer}\left[\left\{\mathrm{HC}(\mathrm{MeCMesN})_{2}\right\} \mathrm{Mg}\right]_{2}$ $\left(\mathrm{Mes}=2,4,6-\mathrm{Me}_{3} \mathrm{C}_{6} \mathrm{H}_{2}\right)^{45}$ yields the unsymmetrical mono NHC-stabilized digermyne $\left(\mathrm{I}^{\mathrm{Pr} 2 \mathrm{Me} 2}\right)\left\{(\mathrm{HCDippN})_{2} \mathrm{~B}\right\} \mathrm{GeGe}\left\{\mathrm{B}(\mathrm{NDippCH})_{2}\right\} \quad$ (2; see Supplementary Figure 15), while the corresponding reaction under forcing conditions with excess potassium metal (or potassium graphite) generates the more highly reduced, formally $\mathrm{Ge}^{0}$ compound $\mathrm{K}_{2}\left[\left\{(\mathrm{HCDippN})_{2} \mathrm{~B}\right\} \mathrm{GeGe}\left\{\mathrm{B}(\mathrm{NDippCH})_{2}\right\}\right]$ (3; Figure 3). Each of these compound types finds precedent in the corresponding chemistry of terphenyl-substituted $\mathrm{Ge}_{2}$ systems, ${ }^{46,47}$ and descriptions of both $\mathbf{2}$ and $\mathbf{3}$ as featuring formal $\mathrm{Ge}=\mathrm{Ge}$ double bonds are consistent with the GeGe distances measured by X-ray crystallography $(2.275(1), 2.392(1) \AA$, respectively). Thus, similar bond lengths have been found for $\left({ }^{t} \mathrm{BuNC}\right) \mathrm{Ar}^{\prime} \mathrm{GeGeAr}^{\prime} \quad(2.343(1) \AA)^{46}$ and 
$\mathrm{K}_{2}\left[\mathrm{Ar}^{*} \mathrm{GeGeAr}^{*}\right](2.391(1) \AA),{ }^{46}$ while the product of the reaction of 2 with dihydrogen, $\left(\mathrm{I}^{\mathrm{P} 2 \mathrm{Me} 2}\right)\left\{(\mathrm{HCDippN})_{2} \mathrm{~B}\right\} \mathrm{GeGe}(\mathrm{H})_{2}\left\{\mathrm{~B}(\mathrm{NDippCH})_{2}\right\}$ (4; see Supplementary Figure 16), features a Ge-Ge single bond and a correspondingly longer separation $(2.453(4) \AA)^{33}\left[\mathrm{Ar}^{\prime}=\mathrm{C}_{6} \mathrm{H}_{3}-2,6-\right.$ $\left.\left(\mathrm{C}_{6} \mathrm{H}_{3}{ }^{i} \mathrm{Pr}_{2}-2,6\right) ; \mathrm{Ar}^{*}=\mathrm{C}_{6} \mathrm{H}_{3}-2,6-\left(\mathrm{C}_{6} \mathrm{H}_{2}{ }^{i} \mathrm{Pr}_{3}-2,4,6\right)\right]$.

Attempted removal of the remaining carbene donor from $\mathbf{2}$ by the use of strong Lewis acids (such as $\mathrm{B}\left(\mathrm{C}_{6} \mathrm{H}_{5}\right)_{3}$ and $\left.\mathrm{B}\left(\mathrm{C}_{6} \mathrm{~F}_{5}\right)_{3}\right)$ proved unsuccessful, so attempts were made to synthesize a neutral, donor-free system of stoichiometry $\mathrm{Ge}_{2}(\text { boryl })_{2}$ by the oxidation of the dianionic component of 3. Accordingly, reaction with two equivalents of $\left[\mathrm{Cp}_{2} \mathrm{Fe}\right]\left[\mathrm{BAr}_{4}^{f}\right]\left(\mathrm{Ar}^{f}=\right.$ $\left.\mathrm{C}_{6} \mathrm{H}_{3}\left(\mathrm{CF}_{3}\right)_{2}-3,5\right)$ in benzene- $\mathrm{d}_{6}$ solution proceeds quantitatively (as determined by in situ multinuclear NMR measurements) generating a species featuring a single boryl ligand environment. Similar chemistry can be effected using the triphenylcarbenium (trityl) oxidant, $\left[\mathrm{Ph}_{3} \mathrm{C}\right]\left[\mathrm{B}\left(\mathrm{C}_{6} \mathrm{~F}_{5}\right)_{4}\right]$, and in this case the product $\left\{(\mathrm{HCDippN})_{2} \mathrm{~B}\right\}_{2} \mathrm{GeGe}(\mathbf{5})$ can be crystallized from pentane solution (in 60-70\% yield) and characterized by X-ray crystallography (Figure 3) in addition to standard spectroscopic and analytical methods.

Structural characterization of digermavinylidene 5. In contrast to the corresponding arylsubstituted systems, $\mathbf{5}$ is shown crystallographically to feature a unique 1,1-disubstitution pattern about the $\mathrm{Ge}_{2}$ fragment, with $\mathrm{Ge}(2)$ being covalently linked only to the other germanium center, $\mathrm{Ge}(1)$. No evidence is obtained from either crystallography (difference Fourier map) or ${ }^{1} \mathrm{H}$ NMR spectroscopy for the presence of any hydrogen atoms attached to $\mathrm{Ge}(2)$. Moreover, in contrast to the geometry observed for digermene systems, $\mathrm{X}_{2} \mathrm{GeGeX}_{2}{ }^{6}$ the four atoms defining the $\mathrm{X}_{2} \mathrm{GeGe}$ 
unit in 5 (i.e. $\mathrm{Ge}(1), \mathrm{Ge}(2), \mathrm{B}(1)$ and $\mathrm{B}(2)$ ) lie within a single plane (largest out-of-plane deviation $=0.03 \AA)$. The $\mathrm{Ge}(1)$-B distances $(2.033(2) \AA)$ are consistent with those measured for other boryl complexes featuring three-coordinate germanium (e.g. 2.057(4) $\AA$ for 2); as with 2 and 3, the Ge-Ge distance $(2.312(1) \AA)$ is within the range expected for a Ge=Ge double bond. ${ }^{6}$ Of additional note regarding the solid state structure of $\mathbf{5}$ is the relatively close approach of one of the flanking aryl rings of each of the boryl ligands to the one-coordinate germanium centre, Ge(2). These are characterized by contacts of 2.904(2) and 2.917(2) $\AA$, and a marked 'canting' of the boryl ligand heterocycle in each case to one side of the Ge-B bond (leading, for example, to disparate $\mathrm{Ge}(1)-\mathrm{B}(1)-\mathrm{N}$ angles of $116.3(1)$ and $\left.139.9(1)^{\circ}\right)$. These structural observations are thought to be linked to the presence of weak stabilizing interactions involving the flanking arene $\pi$ systems and the formally vacant in-plane p orbital at $\mathrm{Ge}(2)$ (vide infra).

Evidence for the retention of these weak $\pi$ interactions in solution is obtained from variable temperature ${ }^{1} \mathrm{H}$ NMR measurements. At room temperature only one signal corresponding to the boryl heterocycle backbone $\mathrm{CH}$ of $\mathbf{5}$ is observed, together with one ${ }^{i} \mathrm{Pr} \mathrm{CH}$ and two ${ }^{i} \mathrm{Pr} \mathrm{CH}_{3}$ resonances for the $\mathrm{C}_{6} \mathrm{H}_{3}{ }^{i} \operatorname{Pr}_{2}-2,6$ groups. Cooling a solution in toluene- $\mathrm{d}_{8}$ to below $213 \mathrm{~K}$, however, results in splitting of each of these signals (see Supplementary Figure 8), consistent with a lower symmetry structure akin to that observed in the solid state (and slow fluxional interconversion on the NMR timescale). From these measurements a value for $\Delta \mathrm{G}^{\ddagger}$ can be obtained which defines an upper limit for the energy associated with the $\operatorname{Ge}(2)$-arene $\pi$ interactions $\left(43 \mathrm{~kJ} \mathrm{~mol}^{-1}\right) .{ }^{48}$ From a mechanistic perspective, this barrier is closely comparable to the energy calculated by DFT methods for a mono-bridged Ge( $\mu$-boryl)Ge(boryl) transition state (akin to structure $\mathbf{C}$, Figure 1) describing the transfer of one boryl ligand between the germanium 
centres $\left(40 \mathrm{~kJ} \mathrm{~mol}^{-1}\right.$; Supplementary Figure 21$)$. As such, a plausible mechanism for the observed fluxionality involves shuttling of a boryl ligand along the $\mathrm{Ge}_{2}$ vector.

Electronic structure of 5. The 1,1-disubstituted structure of $\mathbf{5}$ observed both in the solid state and in hydrocarbon solution is in line with the results of Density Functional Theory calculations (including dispersion) which reveal that the digermavinylene isomer is ca. $10 \mathrm{~kJ} \mathrm{~mol}^{-1}$ more stable than the alternative (trans-bent) 1,2 system. While these data imply that the energetic difference between the two substitution patterns is small, this idea is consistent with the observed reactivity of $\mathbf{5}$ (vide infra), and it is noteworthy that our calculations carried out using the same method, for related terphenyl systems, $\mathrm{Ge}_{2} \mathrm{Ar}_{2}$, show that the corresponding trans-bent isomer is more stable by $>100 \mathrm{~kJ} \mathrm{~mol}^{-1}{ }^{49}$ The molecular orbital occupancy for $\mathbf{5}$ is consistent with a singlet $\left({ }^{1} \mathrm{~A}_{1}\right)$ ground state, in line with its observed diamagnetism, and with predictions made for both the parent vinylidene $\mathrm{H}_{2} \mathrm{C}=\mathrm{C}$ and its digermanium analogue $\mathrm{H}_{2} \mathrm{Ge}=\mathrm{Ge}$ (Figure 4). ${ }^{15,19,21,22}$ However, the ordering of key molecular orbitals for 5 differs from that found in $\mathrm{H}_{2} \mathrm{C}=\mathrm{C}$ (for which the highest occupied molecular orbital, HOMO, is the C-centered lone pair). ${ }^{50}$ The HOMO for 5 (at $-3.79 \mathrm{eV}$ ) is the $\mathrm{GeGe} \pi$ bond, with the HOMO-1 (at $-4.70 \mathrm{eV}$ ) possessing the predominant $\mathrm{Ge}(2)$-centered lone pair character. These differences are in line with expectations of E-E $\pi$ bond strengths on descending group 14, i.e. with the much more weakly stabilized (higher lying) nature of the Ge-Ge $\pi$-bonding molecular orbital than its C-C counterpart. ${ }^{6}$ In common with $\mathrm{H}_{2} \mathrm{C}=\mathrm{C}$, however, the lowest unoccupied molecular orbital (LUMO; $-2.24 \mathrm{eV}$ ) is the formally vacant $\mathrm{Ge}(2) \mathrm{p} \pi$ orbital which lies in the $\mathrm{B}_{2} \mathrm{GeGe}$ plane (and points towards the flanking aryl $\pi$ systems), with the Ge-Ge $\pi^{*}$ orbital (the LUMO+1) being a further $0.27 \mathrm{eV}$ higher in energy. Accordingly, the electronic spectrum of 5 (Supplementary Figure 13) contains 
a very strong band at $460 \mathrm{~nm}$ which features significant a contribution from the $\mathrm{Ge}=\mathrm{Ge} \pi$ to $\pi^{*}$ transition. Finally, in line with the notion of stabilization of the in-plane p orbital at $\mathrm{Ge}(2)$ via a weak arene $\pi$ interaction, it is possible to identify a low-lying orbital (HOMO-11, $-6.37 \mathrm{eV}$ ) which features an in-phase interaction between the Ge $p_{\mathrm{x}}$ orbital and the respective flanking arene $\pi$-systems, albeit with a relatively small germanium contribution (ca. 3\%; Supplementary Figure 22).

Reactivity. The synthesis of $\mathbf{5}$ from $\mathbf{3}$ illustrates the lability of the boryl ancillary ligands about the $\mathrm{Ge}_{2}$ unit, a factor which is additionally reflected in the reaction chemistry of 5 (Figure 2). Thus, the 1,2-disubstitution pattern can be re-established by the addition of potassium graphite, $\mathrm{KC}_{8}$ (which regenerates 3 ), or by the addition of $\mathrm{I}^{\mathrm{Pr} 2 \mathrm{Me} 2}$ (which yields mono-NHC adduct 2 ). The highly unsaturated nature of $\mathbf{5}$, and its relatively small HOMO-LUMO gap (ca. $150 \mathrm{~kJ} \mathrm{~mol}^{-1}$ ) also suggest that it should activate dihydrogen under mild conditions. ${ }^{33}$ This hypothesis is borne out by experiment: 5 takes up two equivalents of $\mathrm{H}_{2}$ at 4 atm pressure and $318 \mathrm{~K}$. The product so generated, however, is shown by both ${ }^{1} \mathrm{H}$ NMR and X-ray crystallography to be the symmetrical 1,2-diboryl-digermane $\quad\left\{(\mathrm{HCDippN})_{2} \mathrm{~B}\right\}(\mathrm{H})_{2} \mathrm{GeGe}(\mathrm{H})_{2}\left\{\mathrm{~B}(\mathrm{NDippCH})_{2}\right\} \quad(\mathbf{6} ; \quad$ Figure 5 and Supplementary Figure 17). Consistent with the idea of ready boryl migration under such conditions, the presumed intermediate of composition (boryl) ${ }_{2} \mathrm{Ge}_{2}(\mathrm{H})_{2}$ (that is, the product of uptake of the first equivalent of $\mathrm{H}_{2}$ ) is calculated to prefer a 1,2-diboryl-digermene geometry over other less symmetrical alternatives by $>20 \mathrm{~kJ} \mathrm{~mol}^{-1}$ (Supplementary Figure 20).

Digermavinylidene 5 is thus uniquely stable as a compound of the type $E_{2} R_{2}$ featuring a 1,1- 
disubstitution pattern. Steric influences on the relative stabilities of germanium systems of this type have been probed computationally: $\mathrm{H}_{2} \mathrm{GeGe}$ is calculated to be $36 \mathrm{~kJ} \mathrm{~mol}^{-1}$ more stable than $\mathrm{HGeGeH}$, while related bulky aryl derivatives favour the ArGeGeAr isomer by $>70 \mathrm{~kJ} \mathrm{~mol}^{-1}{ }^{49}$ Although the boryl substituent employed in $\mathbf{5}$ is undoubtedly bulky, the use of a five-membered heterocycle (rather than a six-membered aryl substituent) reduces the steric pressure exerted by the ortho Dipp groups in comparison, for example, with Power's Ar'GeGeAr' system, ${ }^{28}$ particularly given the greater length of Ge-B (vs. Ge-C) bonds in such systems (2.057(4) $\AA$ and 2.033(2) $\AA$ for $\mathbf{2}$ and 5, respectively, vs. 1.996(3) $\AA$ for $\left.A r^{\prime} G e G e A r^{\prime}\right)$. Moreover, the conversion of a digermyne to a digermavinylidene is effectively an intramolecular disproportionation reaction, converting two formally $\mathrm{Ge}^{\mathrm{I}}$ centers to $\mathrm{Ge}^{\mathrm{II}}$ and $\mathrm{Ge}^{0}$. Similar net processes have been reported for group 13 metals in the presence of boryl ligands, with the generation of (boryl) ${ }_{2} \mathrm{M}^{\mathrm{II}}$ radicals $(\mathrm{M}=\mathrm{Ga}, \mathrm{In}, \mathrm{Tl})$ and elemental metal from $\mathrm{M}^{\mathrm{I}}$ precursors being driven, at least in part, by the stabilization of the higher oxidation state by the strongly $\sigma$-donating boryl group. ${ }^{41}$ The observation of the digermavinylidene structure for $\mathbf{5}$, conceivably relies on similar electronic effects promoting the formation of $\mathrm{Ge}^{\mathrm{II}}$, allied to (weak) arene $\pi$-stabilization of the $\mathrm{Ge}^{0}$ center by the flanking Dipp groups.

\section{Methods}

Manipulations were carried out under a dry, oxygen-free argon or dinitrogen atmosphere, with reagents dissolved or suspended in aprotic solvents, and combined or isolated using cannula and glove box techniques. $\left(\mathrm{I}^{\mathrm{P} 2 \mathrm{Me} 2}\right) \mathrm{GeCl}\left\{\mathrm{B}(\mathrm{NDippCH})_{2}\right\}$ (1) was synthesized from $\left(\mathrm{I}^{\mathrm{Pr} 2 \mathrm{Me} 2}\right) \mathrm{GeCl}_{2}$ and (thf $)_{2} \mathrm{Li}\left\{\mathrm{B}(\mathrm{NDippCH})_{2}\right\}$ in diethyl ether. $\left(\mathrm{I}^{\mathrm{Pr} 2 \mathrm{Me} 2}\right)\left\{(\mathrm{HCDippN})_{2} \mathrm{~B}\right\} \mathrm{GeGe}\left\{\mathrm{B}(\mathrm{NDippCH})_{2}\right\}$ (2) and $\mathrm{K}_{2}\left[\left\{(\mathrm{HCDippN})_{2} \mathrm{~B}\right\} \mathrm{GeGe}\left\{\mathrm{B}(\mathrm{NDippCH})_{2}\right\}\right]$ (3) were synthesized from $\mathbf{1}$ via reduction chemistry 
in toluene solution using $\left[\left\{\mathrm{HC}(\mathrm{MeCMesN})_{2}\right\} \mathrm{Mg}\right]_{2}\left(\mathrm{Mes}=2,4,6-\mathrm{Me}_{3} \mathrm{C}_{6} \mathrm{H}_{2}\right)$ and potassium graphite, respectively. $\mathbf{2}$ was recrystallized from hexane, $\mathbf{3}$ from a $c a .2: 1$ mixture of hexane and toluene. $\left\{(\mathrm{HCDippN})_{2} \mathrm{~B}\right\}_{2} \mathrm{GeGe}(\mathbf{5})$ was synthesized by adding a solution of $\mathbf{3}$ in benzene to two equivalents of either $\left[\mathrm{Cp}_{2} \mathrm{Fe}\right]\left[\mathrm{BAr}_{4}^{f}\right]$ or $\left[\mathrm{Ph}_{3} \mathrm{C}\right]\left[\mathrm{B}\left(\mathrm{C}_{6} \mathrm{~F}_{5}\right)_{4}\right]$, and recrystallized from pentane. The germanium hydrides $\quad\left(\mathrm{I}^{\mathrm{Pr} 2 \mathrm{Me} 2}\right)\left\{(\mathrm{HCDippN})_{2} \mathrm{~B}\right\} \mathrm{GeGe}(\mathrm{H})_{2}\left\{\mathrm{~B}(\mathrm{NDippCH})_{2}\right\} \quad$ (4) and $\left\{(\mathrm{HCDippN})_{2} \mathrm{~B}\right\}(\mathrm{H})_{2} \mathrm{GeGe}(\mathrm{H})_{2}\left\{\mathrm{~B}(\mathrm{NDippCH})_{2}\right\}(\mathbf{6})$ were synthesized from solutions of $\mathbf{2}$ and $\mathbf{5}$, respectively (in hexane or pentane), by exposure to $\mathrm{H}_{2}$. Reaction of 5 with potassium graphite led to the regeneration of $\mathbf{3}$, while reaction of $\mathbf{5}$ with $\mathrm{I}^{\mathrm{Pr} 2 \mathrm{Me} 2}$ was shown to give rise to mono-carbene adduct $\mathbf{2}$. We characterized new compounds by elemental analysis, UV/Visible spectroscopy (for compounds $\mathbf{2}, \mathbf{3}$ and $\mathbf{5}$ which contain $\mathrm{Ge}=\mathrm{Ge}$ double bonds), cyclic voltammetry (for $\mathbf{2}$ and $\mathbf{5}$ ), and multinuclear NMR spectroscopy; the structures of all new compounds $\mathbf{1}-\mathbf{6}$ in the solid state were determined by single-crystal X-ray diffraction studies. Density Functional Theory (DFT), as implemented in the Amsterdam Density Functional code, has been employed to calculate molecular geometries, orbital energies and compositions, and electronic transition energies. 


\section{References}

1. DeKock, R. L. \& Gray H. B. Chemical structure and bonding. (University Science Books, Sausalito, 1989).

2. Simonetta, M. \& Gavezzotti, A in Patai, S., Ed. The chemistry of the carbon-carbon triple bond. (Wiley, New York 1978).

3. Kekulé, A. Sur la constitution des substances aromatiques. Bull. Soc. Chim. Fr. 3, 98-110 (1865).

4. Cava, M. P. \& Mitchell, M. J. Cyclobutadiene and Related Compounds. (Academic Press, New York, 1967).

5. Eaton, P. E. \& Cole, T. W. Cubane. J. Am. Chem. Soc. 86, 3157-3158 (1964).

6. Fischer, R. C. \& Power, P. P. $\pi$-Bonding and the lone pair effect in multiple bonds involving heavier main group elements: developments in the new millennium. Chem. Rev. 110, 38773923 (2010).

7. Power, P. P. Bonding and reactivity of heavier group 14 element alkyne analogues. Organometallics 26, 4362-4372 (2007).

8. Lee, V. Y. \& Sekiguchi, A. Aromaticity of group 14 organometallics: experimental aspects. Angew. Chem. Int. Ed. 46, 6596-6620 (2007).

9. Abersfelder, K., White, A. J. P., Rzepa, H. S., Scheschkewitz, D. A tricyclic aromatic isomer of hexasilabenzene. Science 327, 564-566 (2010).

10. Power, P. P. Main-group elements as transition metals. Nature 463, 171-177 (2010).

11. Stang, P. J. Unsaturated carbenes. Chem. Rev. 78, 383-405 (1978).

12. Bruce, M. I. Organometallic chemistry of vinylidene and related unsaturated carbenes. Chem. Rev. 91, 197-257 (1991). 
13. Ervin, K. M., et al. Bond strengths of ethylene and acetylene. J. Am. Chem. Soc. 112, 57505759 (1990).

14. Krishnan, R., Frisch, M. J., Pople, J. A. \& Schleyer, P. v. R. The vinylidene-acetylene isomerization barrier. Chem. Phys. Lett. 79, 408-411 (1981).

15. Osamura, Y. Schaefer, H. F., III, Gray, S. K. \& Miller, W. H. Vinylidene: a very shallow minimum on the $\mathrm{C}_{2} \mathrm{H}_{2}$ potential energy surface. J. Am. Chem. Soc. 103, 1904-1907 (1981).

16. Chang, N.-Y. Shen, M.-Y. \& Yu, C.-H. Extended $a b$ initio studies of the vinylideneacetylene rearrangement. J. Chem. Phys. 106, 3237-3242 (1997).

17. Stanton, J. F. \& Gauss, J. Some predictions relevant to future spectroscopic observation of $S_{1}$ vinylidene. J. Chem. Phys. 101, 3001-3005 (1994).

18. Breidung, J., et al. Difluorovinylidene, $\mathrm{F}_{2} \mathrm{C}=\mathrm{C}$. Angew. Chem. Int. Ed. Engl. 36, 1983-1985 (1997).

19. Brody, H. K., Magers, D. H. \& Leszczyński, J. Ab initio studies of methylenecarbene and isoelectronic species. Struct. Chem. 6, 293-300 (1995).

20. Nagase, S., Kobayashi, K. \& Takagi, N. Triple bonds between heavier Group 14 elements. A theoretical approach. J. Organomet. Chem. 611, 264-271 (2000).

21. Lein, M., Krapp, A. \& Frenking, G. Why do the heavy-atom analogues of acetylene $\mathrm{E}_{2} \mathrm{H}_{2}(\mathrm{E}$ $=\mathrm{Si}-\mathrm{Pb}$ ) exhibit unusual structures? J. Am. Chem. Soc. 127, 6290-6299 (2005).

22. Landis, C. R. \& Weinhold, F. Origin of trans-bent geometries in maximally bonded transition metal and main group molecules. J. Am. Chem. Soc. 128, 7335-7345 (2006).

23. Rivard, E. Group 14 inorganic hydrocarbon analogues. Chem. Soc. Rev. 45, 989-1003 (2016). 
24. Harper, W. W., et al. Laser spectroscopic detection of the simplest unsaturated silylene and germylene. J. Am. Chem. Soc. 119, 8361-8362 (1997).

25. Chardonnier, M., Bogey, M., Demuynck, C. \& Destombes, J.-L. Nonclassical structures in silicon-containing molecules: the monobridged isomer of $\mathrm{Si}_{2} \mathrm{H}_{2}$. J. Chem. Phys. 97, 79847989 (1992).

26. Pu, L., Twamley, B. \& Power, P. P. Synthesis and characterization of 2,6Trip ${ }_{2} \mathrm{H}_{3} \mathrm{C}_{6} \mathrm{PbPbC}_{6} \mathrm{H}_{3}-2,6-\operatorname{Trip}_{2}$ (Trip $=\mathrm{C}_{6} \mathrm{H}_{2}-2,4,6-i-\mathrm{Pr}_{3}$ ): a stable heavier group 14 element analogue of an alkyne. J. Am. Chem. Soc. 122, 3524-3525 (2000).

27. Phillips, A. D., Wright, R. J., Olmstead, M. M. \& Power P. P. Synthesis and characterization of 2,6-Dipp $2-\mathrm{H}_{3} \mathrm{C}_{6} \mathrm{SnSnC}_{6} \mathrm{H}_{3}-2,6-\mathrm{Dipp}_{2}\left(\mathrm{Dipp}=\mathrm{C}_{6} \mathrm{H}_{3}-2,6-\mathrm{Pr}_{2}^{\mathrm{i}}\right)$ : a tin analogue of an alkyne. J. Am. Chem. Soc. 124, 5930-5931 (2002).

28. Stender, M., Phillips, A. D., Wright, R. J. \& Power, P. P. Synthesis and characterization of a digermanium analogue of an alkyne. Angew. Chem. Int. Ed. 41, 1785-1787 (2002).

29. Sekiguchi, A., Kinjo, R. \& Ichinohe, M. A stable compound containing a silicon-silicon triple bond. Science 305, 1755-1757 (2004).

30. Jana, A., Huch, V. \& Scheschkewitz, D. NHC-stabilized silagermenylidene: a heavier analogue of vinylidene. Angew. Chem. Int. Ed. 52, 12179-12182 (2013).

31. Jana, A., Majumdar, M., Huch, V., Zimmer, M. \& Scheschkewitz, D. NHC-coordinated silagermenylidene functionalized in allylic position and its behaviour as a ligand. Dalton Trans. 43, 5175-5181 (2014).

32. Ghana, P., Arz, M. I., Das, U., Schnakenburg, G. \& Filippou, A. C. Si=Si double bonds: synthesis of an NHC-stabilized disilavinylidene. Angew. Chem. Int. Ed. 54, 9980-9985 (2015). 
33. Leung, W. P., Chan, Y.-C. \& So, C.-W. Chemistry of heavier group 14 base-stabilized heterovinylidenes. Organometallics 34, 2067-2085 (2015).

34. Spikes, G. H., Fettinger, J. C. \& Power, P. P. Facile activation of dihydrogen by an unsaturated heavier main group compound. J. Am. Chem. Soc. 127, 12232-12233 (2005).

35. Fischer, R. C., Pu, L., Fettinger, J. C., Brynda, M. A. \& Power, P. P. Very large changes in bond length and bond angle in a heavy group 14 element alkyne analogue by modification of a remote ligand substituent. J. Am. Chem. Soc. 128, 11366-11367 (2006).

36. Sugiyama, Y., et al. Synthesis and properties of a new kinetically stabilized digermyne: new insights for a germanium analogue of an alkyne. J. Am. Chem. Soc. 128, 1023-1031 (2006).

37. Li, J., Schenk, C., Goedecke, C., Frenking, G. \& Jones, C. A digermyne with a Ge-Ge single bond that activates dihydrogen in the solid state. J. Am. Chem. Soc. 133, 18622-18625 (2011).

38. Hadlington, T. J., Hermann, M., Li, J., Frenking, G. \& Jones, C. Activation of $\mathrm{H}_{2}$ by a multiply bonded amido-digermyne: evidence for the formation of a hydrido-germylene. Angew. Chem. Int. Ed. 52, 10199-10203 (2013).

39. Sasamori, T., et al. Synthesis and reactions of a stable 1,2-diaryl-1,2-dibromodisilene: a precursor for substituted disilenes and a 1,2-diaryldisilyne. J. Am. Chem. Soc. 130, 1385613857 (2008).

40. Protchenko, A. V., et al. A stable two-coordinate acyclic silylene. J. Am. Chem. Soc. 134, 6500-6503 (2012).

41. Protchenko, A. V., et al. Stable $\mathrm{GaX}_{2}, \mathrm{InX} \mathrm{I}_{2}$ and $\mathrm{TlX}_{2}$ radicals. Nature Chem. 6, 315-319 (2014). 
42. Braunschweig, H., Dewhurst, R.D. \& Schneider, A. Electron-precise coordination modes of boron-centered ligands. Chem. Rev. 110, 3924-3957 (2010).

43. Segawa, Y., Yamashita, M. \& Nozaki, K. Boryllithium: isolation, characterization, and reactivity as a boryl anion. Science 314, 113-115 (2006).

44. Rupar, P. A., Staroverov, V. N., Ragogna, P. J. \& Baines, K. M. A germanium(II)-centered dication. J. Am. Chem. Soc. 129, 15138-15139 (2007).

45. Green, S. P., Jones, C. \& Stasch, A. Stable magnesium(I) compounds with Mg-Mg bonds. Science 318, 1754-1757 (2007).

46. $\mathrm{Pu}, \mathrm{L}$., et al. Germanium and tin analogues of alkynes and their reduction products. J. Am. Chem. Soc. 125, 11626-11636 (2003).

47. Cui, C., Olmstead, M. M., Fettinger, J. C., Spikes, G. H. \& Power, P. P. Reactions of the heavier group 14 element alkyne analogues Ar'EEAr' $\left(\mathrm{Ar}^{\prime}=\mathrm{C}_{6} \mathrm{H}_{3}-2,6\left(\mathrm{C}_{6} \mathrm{H}_{3}-2,6-\mathrm{Pr}_{2}^{i}\right)_{2} ; \mathrm{E}=\right.$ Ge, Sn) with unsaturated molecules: probing the character of the EE multiple bonds. $J$. Am. Chem. Soc. 127, 17530-17541 (2005).

48. Broeckaert, L., Geerlings, P., Růžička, A., Willem, R. \& De Proft, F. Can aromatic $\pi$-clouds complex divalent germanium and tin compounds? A DFT study. Organometallics 31, 16051617 (2012).

49. Takagi, N. \& Nagase, S. Substituent effects on germanium-germanium and tin-tin triple bonds. Organometallics 20, 5498-5500 (2001).

50. Kostić, N. \& Fenske, R. F. Molecular orbital study of bonding, conformations, and reactivity of transition-metal complexes containing unsaturated organic ligands. Electrophilic and nucleophilic additions to acetylide, vinylidene, vinyl, and carbene ligands. Organometallics 
1, 974-982 (1982). 
Supplementary Information is linked to the online version of the paper at www.nature.com/nature.

Acknowledgments This work was supported by the Marie Curie IEF programme of the European Union (PIEF-GA-2013-622806) and EPSRC (EP/L025000/1).

Author Contributions A.R. synthesized and characterized the compounds. J.C. collected the single-crystal X-ray crystallographic data and solved the crystal structures. A.R. and H.N. carried out the DFT calculations. S.A. generated and managed the project and wrote the manuscript. All authors discussed the results and commented on the manuscript.

Author Information X-ray crystallographic data for compounds 1, 2, 3, 4, 5 and 6 are freely available from the Cambridge Crystallographic Data Centre (CCDC 1447808-1447813). Reprints and permissions information is available at www.nature.com/reprints. The authors declare no competing financial interests. Correspondence and requests for materials should be addressed to S.A. (simon.aldridge@chem.ox.ac.uk).

Competing financial interests The authors declare no competing financial interests. 
Affiliations

${ }^{1}$ Inorganic Chemistry Laboratory, Department of Chemistry, University of Oxford, South Parks Road, Oxford, UK OX1 3QR.

Arnab Rit, ${ }^{1}$ Jesús Campos, ${ }^{1}$ Haoyu Niu, ${ }^{1}$ and Simon Aldridge*,

* To whom correspondence should be addressed. E-mail: simon.aldridge@chem.ox.ac.uk (SA) 


\section{Supplementary Information}

General considerations and starting material preparations; synthetic, spectroscopic and analytical data for new compounds; X-ray crystallographic studies; computational details (including TDDFT); CIFs for all crystal structures. 


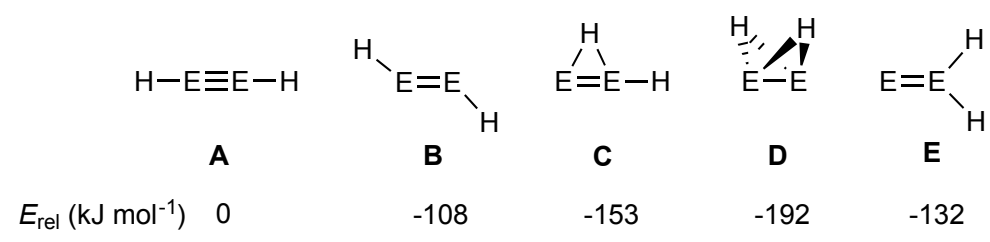

Figure 1. Isomeric forms of $\mathrm{E}_{2} \mathrm{H}_{2}$. Depicted are alkyne-like (A), trans-bent (B), mono- and bis(hydride) bridged $(\mathbf{C}, \mathbf{D})$ and vinylidene isomers $(\mathbf{E})$, with calculated relative energies taken from the literature for $\mathrm{E}=\mathrm{Ge}) .^{20}$<smiles></smiles>

1

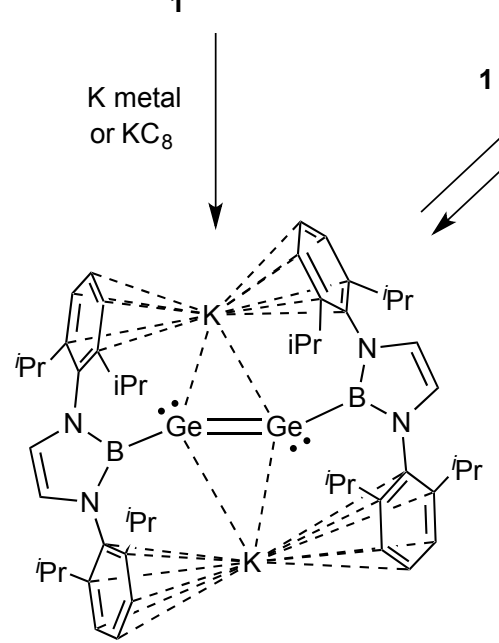

3
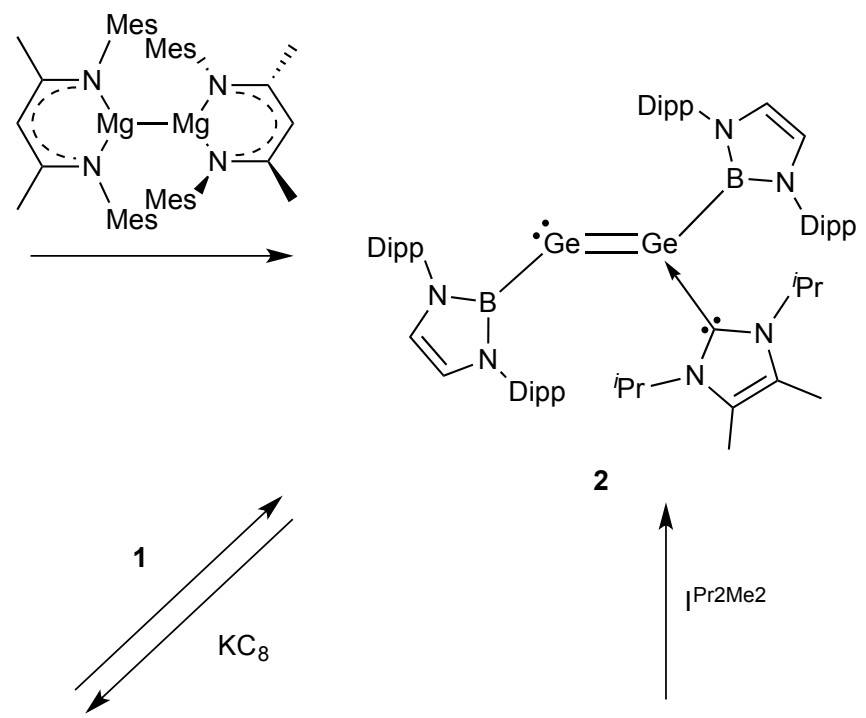

$\mathrm{KC}_{8}$

$\left[\mathrm{Cp}_{2} \mathrm{Fe}\right]\left[\mathrm{BAr}_{4}{ }_{4}\right]$ or $\left[\mathrm{Ph}_{3} \mathrm{C}\right]\left[\mathrm{B}\left(\mathrm{C}_{6} \mathrm{~F}_{5}\right)_{4}\right]$

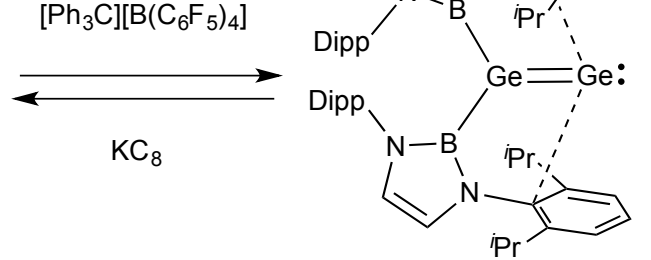

5

Figure 2. Synthesis of digermavinylidene $\mathbf{5}$ and related digermanium systems $\mathbf{2}$ and $\mathbf{3}$. Reduction of NHC-stabilized chlorogermylene 1 yields either the singly base-stabilized $\mathrm{Ge}_{2}^{\mathrm{I}}$ dimer $\mathbf{2}$ (using a $\mathrm{Mg}^{\mathrm{I}}$ reductant), or the more highly reduced base-free $\mathrm{Ge}^{0}{ }_{2}$ dianion $\mathbf{3}$ (using a more powerful 
potassium reducing agent). Subsequent oxidation of $\mathbf{3}$ using two equivalents of a one-electron chemical oxidant (ferrocenium or trityl salts) yields digermavinylidene 5, via a 1,2-boryl migration. $\left[\mathrm{I}^{\mathrm{P} 2 \mathrm{Me} e}=1,3\right.$-diisopropyl-4,5-dimethyl-imidazolylidene; Mes = 2,4,6-trimethylphenyl; Dipp $=2,6$-diisopropylphenyl]

(a)

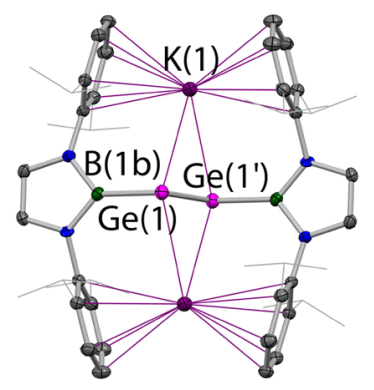

(b)

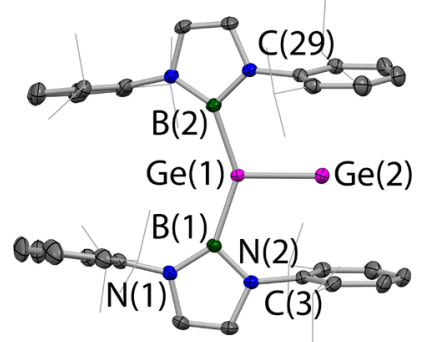

Figure 3. Molecular structures (a) of $\mathbf{3}$, and (b) of $\mathbf{5}$ as determined by X-ray crystallography. Displacement ellipsoids are set at the $40 \%$ level; hydrogen atoms have been omitted and isopropyl groups drawn in wireframe format for clarity. Selected bond distances and angles are as follows: (for 3): Ge(1)-Ge(1') 2.392(1) $\AA, \mathrm{Ge}(1)-\mathrm{B}(1 \mathrm{~b}) 2.097(8) \AA, \mathrm{B}(1 \mathrm{~b})-\mathrm{Ge}(1)-\mathrm{Ge}\left(1^{\prime}\right)$ 102.5(2) ; (for 5): $\mathrm{Ge}(1)-\mathrm{Ge}(2) 2.312(1) \AA ; \mathrm{Ge}(1)-\mathrm{B}(1) 2.033(2) \AA ; \mathrm{Ge}(1)-\mathrm{B}(2) 2.033(2) \AA ;$ $\mathrm{Ge}(2)-\mathrm{C}(3)$ 2.904(2) $\AA$; $\mathrm{Ge}(2)-\mathrm{C}(29)$ 2.917(2) $\AA, \mathrm{B}(1)-\mathrm{Ge}(1)-\mathrm{Ge}(2)$ 108.5(1) ${ }^{\circ}, \mathrm{B}(1)-\mathrm{Ge}(1)-\mathrm{B}(2)$ 142.6(1) ${ }^{\circ}, \mathrm{B}(2)-\mathrm{Ge}(1)-\mathrm{Ge}(2) 108.9(1)^{\circ}, \mathrm{Ge}(1)-\mathrm{B}(1)-\mathrm{N}(1)$ 116.3(1) ${ }^{\circ}, \mathrm{Ge}(1)-\mathrm{B}(1)-\mathrm{N}(2) 139.9(1)^{\circ}$. 

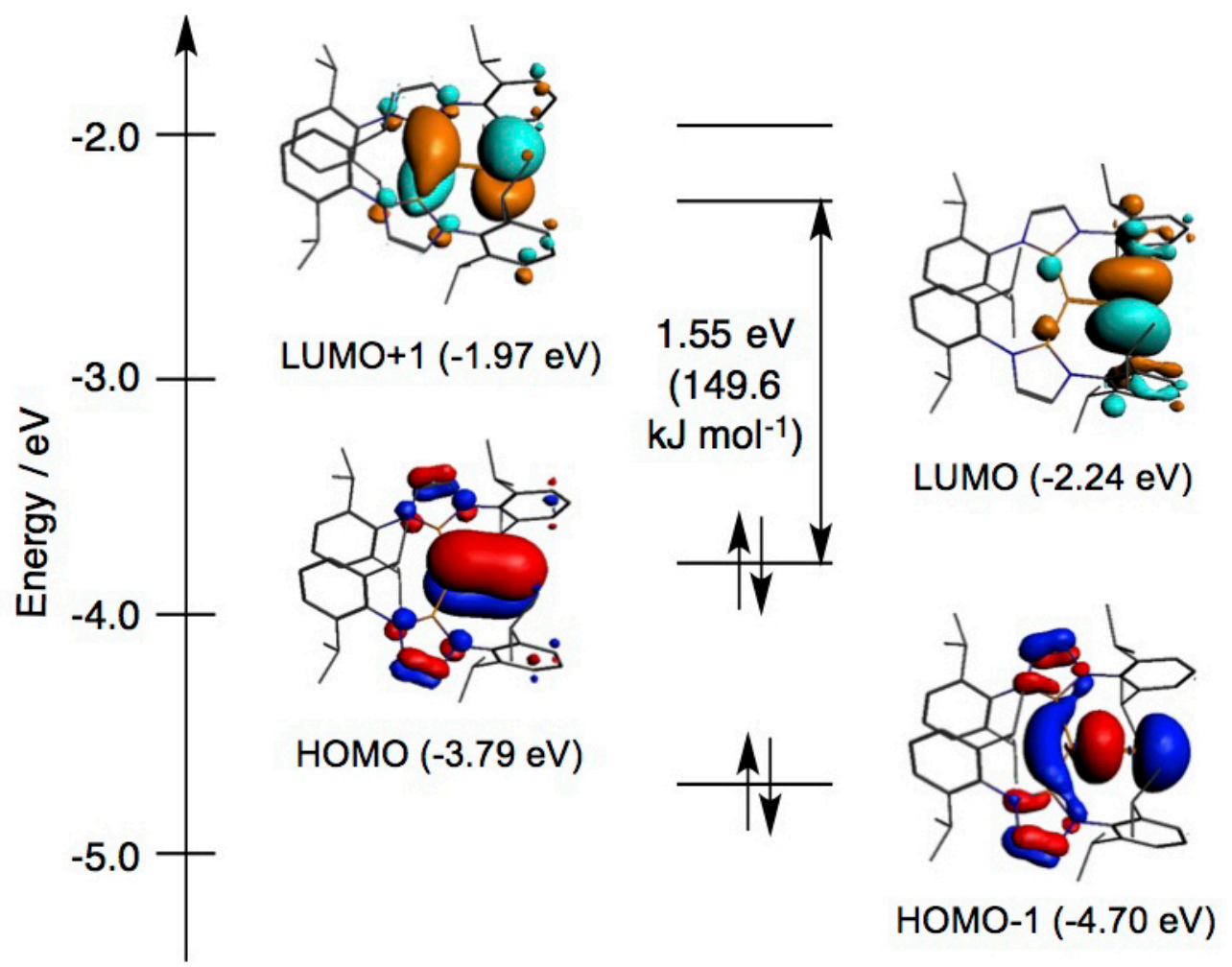

Figure 4. Electron density surfaces and energies for key molecular orbitals of 5. Of the occupied orbitals (which have the phases of the wavefunction depicted in red/dark blue), the HOMO constitutes the GeGe $\pi$-bond, with the lower-lying HOMO-1 possessing lone pair character at the terminal germanium centre. The virtual orbitals depicted (phases shown in brown/pale blue) feature $\pi$-type contributions from the terminal germanium atom either in the $\mathrm{GeB}_{2}$ plane (LUMO) or perpendicular to it (LUMO+1). The latter orbital possesses GeGe $\pi^{*}$ character. $[\mathrm{HOMO}=$ highest occupied molecular orbital; LUMO = lowest unoccupied molecular orbital $]$ 


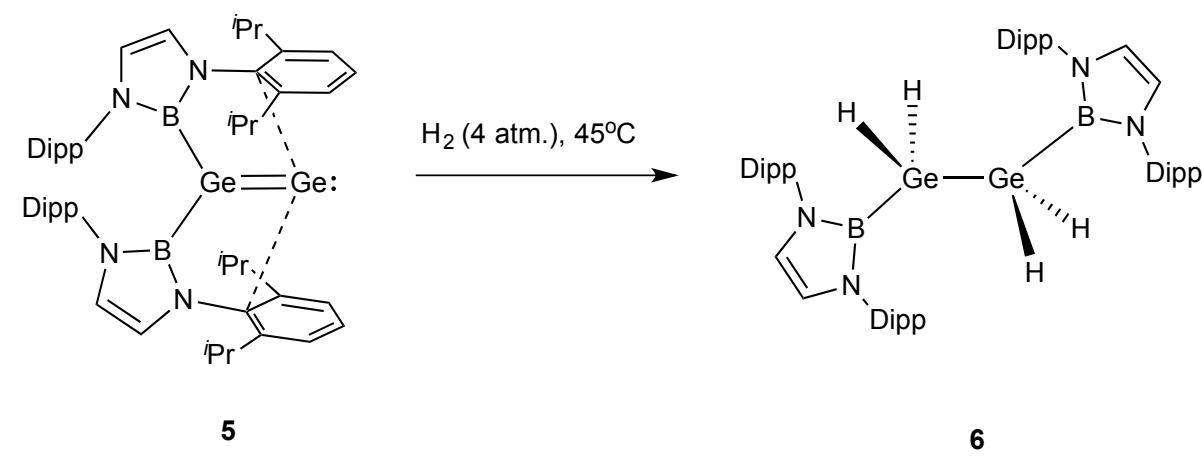

Figure 5. Uptake of dihydrogen by digermavinylidene 5. Reaction of 5 with $\mathrm{H}_{2}$ at ca. $4 \mathrm{~atm}$ pressure and $45^{\circ} \mathrm{C}$ goes to completion over a period of 6 hours, and occurs via the uptake of two equivalents of dihydrogen, with accompanying 1,2-migration of one of the boryl substituents. The symmetrical structure of the resulting diboryldigermane has been confimed by spectroscopic and crystallographic measurements. 